\title{
Produção animal em pastagem de capim-braquiária adubada com nitrogênio
}

[Animal production on nitrogen fertilized signalgrass pasture]

\author{
L.M. Moreira ${ }^{1}$, M.E.R. Santos ${ }^{2}$, D.M. Fonseca ${ }^{2 *}$, J.A. Martuscello ${ }^{3}$, R.V. Morais ${ }^{4}$, C. Mistura ${ }^{5}$ \\ ${ }^{1}$ Faculdade de Estudos Administrativos de Minas Gerais - Belo Horizonte, MG \\ ${ }^{2}$ Departamento de Zootecnia - UFV \\ Av. P. H. Rolfs, $\mathrm{s} / \mathrm{n}^{\circ}$ \\ 36570-000 - Viçosa, MG \\ ${ }^{3}$ Universidade Federal de Alagoas - Arapiraca, AL \\ ${ }^{4}$ Coordenadoria de Assistência Técnica Integral - São José do Rio Pardo, SP \\ ${ }^{5}$ Universidade do Estado da Bahia - Juazeiro, BA
}

\begin{abstract}
RESUMO
O experimento foi realizado em dois anos para avaliar o potencial de produção de bovinos em pastagens de Brachiaria decumbens adubadas com nitrogênio (N). Foram determinadas as massas de forragem total (MFT) e de forragem verde (MFV), a composição morfológica e o valor nutritivo da forragem potencialmente consumível, bem como o desempenho animal e a taxa de lotação (TL) das pastagens. Os tratamentos consistiram de quatro doses de $\mathrm{N}-75,150,225$ e 300kg/ha.ano -, em delineamento de blocos ao acaso, com duas repetições. Nos dois anos, as MFT e MFV aumentaram linearmente em função da aplicação de N. A composição química da forragem potencialmente consumível foi pouco alterada pela aplicação de N. A adubação nitrogenada não influenciou o ganho de peso individual dos novilhos, mas aumentou a TL - de 3,6 para 5,3 e de 3,7 para 5,2UA/ha no primeiro e segundo ano, respectivamente - e a produção animal por área da pastagem - de 404,2 para 737,9 e de 619,7 para 1008,4kg/ha no primeiro e segundo anos, respectivamente.
\end{abstract}

Palavras-chave: bovino de corte, Brachiaria decumbens, desempenho, lotação contínua, simulação de pastejo

\begin{abstract}
The experiment which aimed to evaluate the potential of cattle production on nitrogen-fertilized Brachiaria decumbens pastures was carried out in two years. The total forage mass (TFM), green forage mass (GFM), morphological composition and nutritive value of the potentially consumed forage were determined, as well as the animal performance and the stocking rate (SR). The treatments encompassed four doses of $N$, being 75, 150, 225 and 300kg/ha.year. A randomized block design with two repetitions was used. The chemical composition of the potentially consumable forage was little altered by the $N$ application. $N$-fertilization did not influence the weight gain of steers, but increased the SR from 3.6 to 5.3 in the first year and from 3.7 to 5.2 animal units per hectare in the second year, and the production by area of pasture from 404.2 to $737.9 \mathrm{~kg} / \mathrm{ha}$ in the first year and from 619.7 to $1008.4 \mathrm{~kg} / \mathrm{ha}$ in the second year. $N$-fertilization increases forage mass, stocking rate and animal production by area of pasture on B. decumbens $c v$. Basilisk pastures managed under continuous stocking with varying stocking rate.
\end{abstract}

Keywords: animal performance, Brachiaria decumbens, continuous stocking, hand-plucked

Recebido em 30 de março de 2010

Aceito em 14 de abril de 2011

*Autor para correspondência (corresponding author)

E-mail: dsfonseca@ufv.br 


\section{INTRODUÇÃO}

O gênero Brachiaria, de grande representatividade nos sistemas de produção animal no Brasil, ocupa cerca de $85 \%$ das áreas de pastagens cultivadas e, nesse cenário, a área com Brachiaria decumbens Stapf. destaca-se por representar cerca de 55\% desse total (Macedo, 2004). Apesar da importância econômica da $B$. decumbens para os sistemas pastoris, ainda assim não há informações consistentes que permitam nortear o manejo dessa espécie sob pastejo e adubação.

Em regiões tropicais, a adubação com nitrogênio consiste em estratégia de manejo eficaz na intensificação da produção animal em pastagens (Alvin e Botrel, 2001), pois permite incremento consistente na capacidade de suporte da pastagem e na produção animal por unidade de área, embora com efeitos pouco expressivos sobre o desempenho animal (Euclides et al., 2007). Isso é resultado da maior taxa de acúmulo de forragem obtida nas pastagens adubadas (Lugão et al., 2003; Fagundes et al., 2005; Santos et al., 2009; Vitor et al., 2009).

Quando se trata de adubação dos pastos de $B$. decumbens, muito se discute sobre a possibilidade de ocorrer respostas significativas em produção vegetal e animal. Características da B. decumbens, como baixa exigência em fertilidade de solo, fazem com que essa forrageira seja estabelecida em solos menos férteis e, normalmente, recomendadas para sistemas de baixo nível tecnológico. Nesses sistemas, a adubação nitrogenada é pouco utilizada ou ausente, o que contribui para que os estudos científicos também não insiram a $B$. decumbens dentre as forrageiras a serem avaliadas em condições de maior fertilidade ou níveis mais elevados de adubo.

A assertiva de que a $B$. decumbens não responde ou apresenta resposta reduzida à adubação com nitrogênio pode ser justificada pela não adoção de estratégias de manejo do pastejo adequadas quando os pastos são adubados. Nesse sentido, estudo realizado por Cavalcante (2001) permite inferir que o adequado manejo do pastejo da $B$. decumbens é adotado quando o pasto é mantido com cerca de $20 \mathrm{~cm}$ de altura, sob lotação contínua. Com esse manejo, vislumbra-se a possibilidade de aumentar a eficiência da adoção da estratégia de adubação nitrogenada e, por conseguinte, incrementar a produtividade da pastagem.

Assim, este trabalho teve o objetivo de determinar o potencial de produção animal em pastagens de $B$. decumbens cv. Basilisk adubadas com nitrogênio e manejadas em altura adequada, sob lotação contínua.

\section{MATERIAL E MÉTODOS}

O experimento foi conduzido no setor forragicultura da Universidade Federal de Viçosa, em uma pastagem de Brachiaria decumbens Stapf. cv. Basilisk (capimbraquiária), estabelecida em 1997. A pastagem foi dividida em oito piquetes, cujas áreas variavam de 0,25 a 0,4 ha. $\mathrm{O}$ clima, pelo sistema de Köppen (1948), é do tipo Cwa, com estações seca (maio a outubro) e chuvosa (novembro a abril) bem definidas. A precipitação média anual é de $1.340 \mathrm{~mm}$, com umidade relativa do ar média de $80 \%$ e temperatura média anual de $19^{\circ} \mathrm{C}$, oscilando entre a média das máximas em $22,1^{\circ} \mathrm{C}$ e a média das mínimas em $15^{\circ} \mathrm{C}$. Durante o período experimental, dados climáticos foram registrados (Tab. 1).

O solo da área do experimento é classificado como latossolo vermelho-amarelo, com textura argilosa e relevo medianamente ondulado. Suas características químicas (média das unidades experimentais - piquetes), na camada de 0 a $20 \mathrm{~cm}$ de profundidade, foram: $\mathrm{pH} \mathrm{em} \mathrm{H}_{2} \mathrm{O}-5,2$ (relação 1:2,5); P - 5,18 e K - 148,75mg/dm ${ }^{3}$ (Mehlich-1); $\mathrm{Ca}-2,83, \mathrm{Mg}-0,82$ e $\mathrm{Al}-$ $0,13 \mathrm{cmol}_{\mathrm{c}} / \mathrm{dm}^{3}(\mathrm{KCl}-1 \mathrm{moL} / \mathrm{L})$; soma de bases 4,03 e CTC a pH $7-10,69 \mathrm{cmol}_{\mathrm{c}} / \mathrm{dm}^{3}$; saturação por bases (V) - 37,65 e por alumínio (m) $3,43 \%$; e matéria orgânica $-4,24 \mathrm{dag} / \mathrm{kg}$.

Em novembro de 2001, foi aplicado 0,7t/ha de calcário dolomítico, em cobertura, e nos meses de dezembro de 2001 e novembro de 2002 foram realizadas as adubações fosfatada e potássica. Aplicaram-se, em cobertura, $100 \mathrm{~kg} / \mathrm{ha}$ de $\mathrm{P}_{2} \mathrm{O}_{5}$ na forma de superfosfato simples em toda área experimental. As quantidades de $\mathrm{K}_{2} \mathrm{O}$ aplicadas foram determinadas de forma que as unidades experimentais (piquetes) recebessem doses suficientes para elevar a disponibilidade de potássio no solo para cerca de $150 \mathrm{mg} . \mathrm{dm}^{-3}$. 
Tabela 1. Precipitação pluvial total (PPT) e valores médios de insolação (INS), umidade relativa do ar (UR) e temperatura (mínima, máxima e média), durante dois períodos experimentais

\begin{tabular}{cccccccc}
\hline \multirow{2}{*}{ Período } & Mês/ & PPT & INS & UR & \multicolumn{3}{c}{ Temperatura $\left({ }^{\circ} \mathrm{C}\right)$} \\
\cline { 6 - 8 } & ano & $(\mathrm{mm})$ & $(\mathrm{h} /$ dia $)$ & $(\%)$ & Mínima & Máxima & Média \\
\hline \multirow{6}{*}{ Primeiro ano } & Nov/01 & 231,50 & 4,94 & 81,73 & 18,68 & 27,70 & 22,18 \\
& Dez/01 & 218,30 & 4,55 & 80,56 & 18,75 & 27,09 & 22,02 \\
& Jan/02 & 270,10 & 5,23 & 81,32 & 19,03 & 28,40 & 22,69 \\
& Fev/02 & 279,80 & 3,62 & 82,87 & 19,64 & 27,94 & 22,65 \\
& Mar/02 & 98,50 & 8,52 & 78,32 & 18,29 & 29,63 & 22,57 \\
& Abr/02 & 1,80 & 9,11 & 74,07 & 17,10 & 30,84 & 22,33 \\
\hline \multirow{6}{*}{ Segundo anonyyyyyy} & Nov/02 & 218,20 & 5,55 & 78,75 & 18,14 & 27,82 & 21,86 \\
& Dez/02 & 279,10 & 4,67 & 82,19 & 19,66 & 28,55 & 23,07 \\
& Jan/03 & 432,70 & 3,51 & 84,10 & 20,15 & 28,36 & 23,00 \\
& Fev/03 & 27,90 & 8,55 & 73,79 & 19,08 & 31,10 & 23,76 \\
& Mar/03 & 81,40 & 5,53 & 79,28 & 19,18 & 29,36 & 22,77 \\
& Abr/03 & 16,60 & 6,50 & 80,25 & 16,57 & 28,36 & 21,42 \\
\hline
\end{tabular}

O experimento foi realizado em dois anos agrícolas consecutivos, denominados de primeiro ano - dezembro de 2001 a abril de 2001 - e segundo ano - novembro de 2002 a abril de 2003. Em ambos os anos, os tratamentos consistiram de quatro doses de nitrogênio $(\mathrm{N})$ $75,150,225$ e $300 \mathrm{~kg} / \mathrm{ha}$.ano -, parceladas em três aplicações. O delineamento foi em blocos ao acaso, com duas repetições. No primeiro ano, as três aplicações do adubo nitrogenado ocorreram em 23/01/02, 27/02/02 e 30/03/02, e no segundo ano, em 01/12/02, 01/02/03 e 04/03/03.

Em setembro de 2001, todos os pastos foram submetidos ao pastejo intenso para promover o rebaixamento do capim-braquiária. Após esse pastejo, realizou-se a roçada dos pastos na altura de aproximadamente $10 \mathrm{~cm}$ a partir do nível do solo para padronização.

Após a rebrotação, todos os pastos foram mantidos em altura média de aproximadamente $20 \mathrm{~cm}$, adotando-se o método de pastejo em lotação contínua. Para isso, a altura do pasto foi monitorada duas vezes por semana, com a realização de mensurações aleatórias em 50 pontos por piquete, utilizando-se régua graduada com divisões de $1 \mathrm{~cm}$. O controle da altura do pasto foi realizado por meio de ajustes na taxa de lotação animal, utilizando-se o método put and take. Dois grupos de novilhos foram utilizados. No primeiro, constituído de dois novilhos por piquete, denominado animais testes, os animais permaneceram na área durante todo o período experimental para avaliação de desempenho. No segundo, denominado animais de equilíbrio, os novilhos foram colocados ou retirados dos piquetes quando a altura média do pasto era de 22 e $18 \mathrm{~cm}$, respectivamente. Os novilhos de equilíbrio, quando retirados dos piquetes, foram mantidos em pastagem de 2,5ha de capimbraquiária, contígua à área experimental. Usaram-se novilhos mestiços Holandês x Zebu, não castrados, de características fenotípicas semelhantes e média do peso inicial de $180 \mathrm{~kg}$ e $217 \mathrm{~kg}$ no primeiro e segundo anos, respectivamente.

As avaliações foram iniciadas em janeiro de 2002 - primeiro ano - e dezembro de 2003 segundo ano -, quando houve estabilização da altura do pasto em todos os piquetes, e foram encerradas sempre em 30 de abril em razão das limitações climáticas. Estas não permitiram manter os animais nos piquetes com a altura média do pasto em torno de $20 \mathrm{~cm}$.

Para a determinação das massas de forragem total (MFT) e de forragem verde (MFV), foram colhidas três amostras de forragem por piquete em áreas representativas da condição do pasto, com cerca de $20 \mathrm{~cm}$ de altura. Foi utilizado na amostragem um quadrado de $40 \mathrm{~cm}$ de lado colhendo-se todos os perfilhos contidos no interior do quadrado, com corte efetuado no nível da superfície do solo. As amostras foram pesadas ainda verdes e, em seguida, divididas em duas subamostras de aproximadamente $200 \mathrm{~g}$, sendo uma utilizada para estimar a MFT, e a outra para ser fracionada em MFV - folhas verdes mais colmos verdes - e material morto. As subamostras, acondicionadas em sacos de papel, 
foram pesadas e colocadas em estufa com ventilação forçada a $65^{\circ} \mathrm{C}$, durante 72 horas. Após secagem, as subamostras foram pesadas novamente para estimação do teor de massa seca. Com esses dados, calcularam-se as MFT e MFV, expressas com base na massa seca.

A avaliação da composição química da forragem foi determinada em amostras oriundas de simulação de pastejo. No primeiro ano, as amostragens foram realizadas em 31/01/02, 08/03/02 e 12/04/02, e no segundo ano, em 05/12/02, 09/01/03, 06/02/03, 13/03/03 e 10/04/03.

A simulação de pastejo animal foi realizada por três observadores treinados, sempre pela manhã, procurando colher, manualmente, a forragem com características semelhantes àquela apreendida pelos animais em cada piquete. Cada observador acompanhou pelo menos dois novilhos dentro de um mesmo piquete e simulou o pastejo colhendo aproximadamente $400 \mathrm{~g}$ de forragem. As amostras dos três observadores foram agrupadas para formar uma única amostra por piquete.

As amostras de simulação de pastejo foram colocadas em estufa com ventilação forçada a $65^{\circ} \mathrm{C}$, por 72 horas, para determinar os teores de proteína bruta $(\mathrm{PB})$, fibra em detergente neutro (FDN) e digestibilidade in vitro da massa seca (DIVMS), determinados de acordo com as técnicas descritas por Silva e Queiroz (2002).

O período de adaptação foi de 28 dias nos piquetes, e todos os animais foram pesados após jejum de 15 horas. Outra pesagem foi realizada no final dos períodos experimentais. Com isso, o desempenho individual foi calculado pela diferença no peso dos animais testes entre o início e o término do período de avaliação, e com a informação do número de dias do período de avaliação. No primeiro ano, o desempenho animal foi avaliado no período de 09/01/02 a 30/04/02 - 110 dias -, e no segundo, de 05/12/02 a $30 / 04 / 03$ - 146 dias.

O tempo de permanência dos animais de equilíbrio em cada piquete foi registrado. Assim, ao final do experimento, com o número de dias de permanência dos animais testes e de equilíbrio somados, foi possível o cálculo da taxa de lotação (TL) em cada piquete, expressa em $\mathrm{UA} /$ ha (unidade animal $=450 \mathrm{~kg}$ ). A produção por unidade de área (PA), expressa em $\mathrm{kg} / \mathrm{ha}$, foi calculada pelo produto do desempenho animal (kg/novilho.dia) e o número de dias.novilho/ha.

As análises estatísticas foram realizadas pelo SAEG (Sistema..., 2003). Para cada característica, procedeu-se à análise de variância e, posteriormente, a análises de regressão, com seleção de modelos lineares e quadráticos significativos até $5 \%$ de probabilidade, pelo teste $\mathrm{t}$.

\section{RESULTADOS E DISCUSSÃO}

A altura do pasto durante o período experimental ficou próxima à meta estabelecida, $20 \mathrm{~cm}$ no primeiro ano e $20,4 \mathrm{~cm}$ no segundo ano de avaliação (Tab. 2). Contudo, houve heterogeneidade na altura dos pastos, fato comprovado pelos desvios-padrão de 9,4 e $7,0 \mathrm{~cm}$ no primeiro e segundo anos, respectivamente. Isso ocorreu porque os bovinos não pastejam de forma uniforme. Essa variação também foi observada por Cavalcante (2001) em pastos de $B$. decumbens sob lotação contínua. $\mathrm{O}$ manejo em lotação contínua, quando comparado à lotação intermitente, tem essa característica de possibilitar maior ocorrência de desuniformidade de pastejo (Barthram et al., 2005).

As MFT e MFV aumentaram linearmente $(\mathrm{P}<0,01)$ conforme aumento da dose de nitrogênio, nos dois anos de avaliação (Tab. 3), mesmo com a altura dos pastos mantida a $20 \mathrm{~cm}$ em todos os piquetes. Isso ocorreu porque os pastos com maior dose de $\mathrm{N}$ apresentam alteração em sua estrutura, caracterizada pelo maior número de perfilhos vivos, conforme observaram Fagundes et al. (2006) e Moraes et al. (2006). De fato, um dos processos responsáveis pelo incremento da massa e da produção de forragem na pastagem adubada com $\mathrm{N}$ é o aumento na capacidade de perfilhamento do pasto. 
Tabela 2. Valores médios quinzenais das alturas e desvios-padrão $(\mathrm{cm})$ do pasto de Brachiaria decumbens cv. Basilisk, nas diferentes doses de nitrogênio $(\mathrm{N})$ aplicadas e meses de avaliação

\begin{tabular}{|c|c|c|c|c|c|}
\hline \multirow{2}{*}{$\begin{array}{l}\text { Quinzena/ } \\
\text { mês }\end{array}$} & \multicolumn{4}{|c|}{ Tratamento $(\mathrm{kg} / \mathrm{ha}$ de $\mathrm{N})$} & \multirow{2}{*}{ Média mensal } \\
\hline & 75 & 150 & 225 & 300 & \\
\hline \multicolumn{6}{|c|}{ Primeiro ano (2002) } \\
\hline $1 \%$ jan & $20,4 \pm 10,3$ & $22,7 \pm 10,0$ & $21,6 \pm 11,8$ & $25,7 \pm 13,1$ & \multirow{2}{*}{$21,2 \pm 10,6$} \\
\hline $2^{\mathrm{a}} / \mathrm{jan}$ & $20,4 \pm 9,9$ & $20,1 \pm 10,1$ & $19,0 \pm 10,2$ & $19,4 \pm 9,8$ & \\
\hline $1^{\mathrm{a}} / \mathrm{fev}$ & $19,4 \pm 8,4$ & $18,6 \pm 8,3$ & $19,6 \pm 9,6$ & $18,5 \pm 9,0$ & \multirow{2}{*}{$19,2 \pm 8,8$} \\
\hline $2^{\mathrm{a}} / \mathrm{fev}$ & $18,9 \pm 8,7$ & $20,1 \pm 8,1$ & $18,8 \pm 9,0$ & $20,1 \pm 9,1$ & \\
\hline $1^{\mathrm{a} / \mathrm{mar}}$ & $20,7 \pm 10,2$ & $21,0 \pm 10,0$ & $20,4 \pm 10,4$ & $20,8 \pm 11,7$ & \multirow{2}{*}{$20,2 \pm 10,2$} \\
\hline $2 \mathrm{a} / \mathrm{mar}$ & $19,4 \pm 9,8$ & $19,4 \pm 8,9$ & $20,1 \pm 9,4$ & $20,2 \pm 10,9$ & \\
\hline $1^{\mathrm{a}} / \mathrm{abr}$ & $19,0 \pm 8,2$ & $20,8 \pm 8,1$ & $20,7 \pm 10,0$ & $20,4 \pm 9,3$ & \multirow{2}{*}{$19,5 \pm 8,2$} \\
\hline $2^{\mathrm{a}} / \mathrm{abr}$ & $18,6 \pm 7,4$ & $19,3 \pm 7,0$ & $18,8 \pm 7,6$ & $18,3 \pm 7,8$ & \\
\hline Média & $19,6 \pm 9,1$ & $20,2 \pm 8,8$ & $19,9 \pm 9,7$ & $20,4 \pm 10,1$ & $20,0 \pm 9,4$ \\
\hline \multicolumn{6}{|c|}{ Segundo ano (2002 e 2003) } \\
\hline $1 \% / \mathrm{dez}$ & $20,9 \pm 8,1$ & $21,3 \pm 8,4$ & $25,6 \pm 10,9$ & $22,7 \pm 11,7$ & \multirow{2}{*}{$23,2 \pm 9,6$} \\
\hline $2^{\mathrm{a} / \mathrm{dez}}$ & $20,9 \pm 8,8$ & $23,8 \pm 9,3$ & $24,7 \pm 9,8$ & $26,0 \pm 9,8$ & \\
\hline $1^{\mathrm{a} / \mathrm{jan}}$ & $20,7 \pm 9,4$ & $23,1 \pm 10,4$ & $23,0 \pm 7,7$ & $22,8 \pm 8,4$ & \multirow{2}{*}{$21,4 \pm 7,9$} \\
\hline $2^{\mathrm{a} / \mathrm{jan}}$ & $21,4 \pm 6,9$ & $21,7 \pm 7,2$ & $18,6 \pm 6,1$ & $19,7 \pm 7,2$ & \\
\hline $1^{\mathrm{a}} / \mathrm{fev}$ & $20,7 \pm 7,2$ & $20,2 \pm 5,8$ & $20,1 \pm 5,2$ & $20,8 \pm 6,3$ & \multirow{2}{*}{$20,2 \pm 6,2$} \\
\hline $2^{\mathrm{a} / \mathrm{fev}}$ & $19,6 \pm 7,4$ & $20,3 \pm 6,1$ & $19,6 \pm 5,3$ & $20,2 \pm 6,4$ & \\
\hline $1^{\mathrm{a} / \mathrm{mar}}$ & $17,6 \pm 5,5$ & $19,0 \pm 5,8$ & $18,4 \pm 4,7$ & $18,2 \pm 6,1$ & \multirow{2}{*}{$18,0 \pm 5,4$} \\
\hline $2 \mathrm{a} / \mathrm{mar}$ & $16,8 \pm 5,9$ & $18,5 \pm 5,2$ & $17,3 \pm 4,1$ & $18,1 \pm 6,1$ & \\
\hline $1^{a} / \mathrm{abr}$ & $18,8 \pm 6,5$ & $22,1 \pm 6,2$ & $20,4 \pm 5,3$ & $21,4 \pm 8,2$ & \multirow{2}{*}{$19,5 \pm 5,9$} \\
\hline $2^{\mathrm{a} / a b r}$ & $17,8 \pm 6,1$ & $19,1 \pm 5,3$ & $18,4 \pm 3,8$ & $18,1 \pm 5,8$ & \\
\hline Média & $19,5 \pm 7,2$ & $20,9 \pm 7,0$ & $20,6 \pm 6,3$ & $20,8 \pm 7,6$ & $20,4 \pm 7,0$ \\
\hline
\end{tabular}

Tabela 3. Equações de regressão ajustadas para massa de forragem total (MFT) e massa de forragem verde (MFV) em função das doses de N, em pastagem de Brachiaria decumbens, no primeiro e segundo anos

\begin{tabular}{llc}
\hline Característica & Equação de regressão & $\mathrm{R}^{2}$ \\
\hline MFT $(\mathrm{kg} / \mathrm{ha})$ & Primeiro ano & 0,91 \\
$\operatorname{MFV}(\mathrm{kg} / \mathrm{ha})$ & $\hat{Y}=6.227,42+7,39543 * * \mathrm{~N}$ & 0,90 \\
& $\hat{Y}=3.970,30+6,33153 * * \mathrm{~N}$ & \\
MFT $(\mathrm{kg} / \mathrm{ha})$ & Segundo ano & 0,99 \\
MFV $(\mathrm{kg} / \mathrm{ha})$ & $\hat{Y}=6.953,57+9,35979 * * \mathrm{~N}$ & 0,98 \\
\hline
\end{tabular}

** Significativo pelo teste $\mathrm{t}(\mathrm{P}<0,01)$.

Vale ressaltar as variações das estruturas nos pastos de capim-braquiária mantidos com mesma altura média $-20 \mathrm{~cm}-$ em decorrência da adubação nitrogenada. Esta proporcionou maiores MFT e MFV, o que resultou no incremento da densidade de forragem. Maior densidade volumétrica da forragem pode alterar o comportamento ingestivo de bovinos em pastejo, pois é um dos determinantes da massa do bocado, característica positivamente associada ao consumo e ao desempenho animal (Stobbs, 1975).

Os teores de proteína bruta (PB) da forragem potencialmente consumível aumentaram linearmente em função das doses de $\mathrm{N}$ no primeiro $(\mathrm{P}<0,05)$ e segundo $(\mathrm{P}<0,01)$ anos $(\mathrm{Tab}$. 4). Para as doses de 75 e $300 \mathrm{~kg} / \mathrm{ha}$, registraram- 
se, respectivamente, valores de 9,9 e $14,5 \%$ no primeiro ano e 9,6 e $13,6 \%$ de $\mathrm{PB}$ no segundo ano. As eficiências foram de aproximadamente 0,02 e 0,01 unidade percentual de $\mathrm{PB}$ por quilograma de N/ha no primeiro e segundo anos, respectivamente. Essas respostas são modestas e evidenciam que a aplicação de $\mathrm{N}$ na pastagem tem efeito limitado em melhorar a qualidade da forragem consumida pelos animais. $\mathrm{O}$ aumento no teor de PB da forragem com a adubação nitrogenada também tem sido verificado em outros trabalhos de pesquisa (Correa et al., 2007; Mistura et al., 2007; Vitor et al., 2009).

Tabela 4. Equações de regressão ajustadas para os teores de proteína bruta (PB), fibra em detergente neutro (FDN) e coeficientes de digestibilidade in vitro da massa seca (DIVMS) da Brachiaria decumbens, em função das doses de nitrogênio $(\mathrm{N})$ no primeiro e segundo anos

\begin{tabular}{lcc}
\hline Característica & Equação de regressão & $\mathrm{R}^{2}$ \\
\hline PB $(\%)$ & Primeiro ano & 0,91 \\
FDN $(\%)$ & $\hat{Y}=8,33+0,02064 * \mathrm{~N}$ & - \\
DIVMS $(\%)$ & $\bar{Y}=72,97$ & 0,99 \\
& $\hat{Y}=81,49-0,1088 * \mathrm{~N}+0,00035 * \mathrm{~N}^{2}$ & 0,99 \\
PB $(\%)$ & Segundo ano & - \\
FDN $(\%)$ & $\hat{Y}=8,28+0,01784 * * \mathrm{~N}$ & - \\
DIVMS $(\%)$ & $\bar{Y}=76,30$ & \\
\hline$* *$ Significativo pelo teste $\mathrm{t}(\mathrm{P}<0,01) ; *$ Significativo pelo teste $\mathrm{t}(\mathrm{P}<0,05)$. &
\end{tabular}

Diferentemente do percentual de $\mathrm{PB}$, não houve influência $(\mathrm{P}>0,05)$ da dose de $\mathrm{N}$ nos teores de FDN da forragem potencialmente consumível (Tab. 4) no primeiro $(72,9 \%)$ e segundo anos (76,3\%). Os valores de FDN foram altos e podem afetar o desempenho animal, pois teores acima de 55 a $60 \%$ correlacionam-se negativamente com o consumo de pasto (Van Soest, 1965).

O coeficiente de DIVMS da forragem potencialmente consumível foi alterado $(\mathrm{P}<0,05)$ apenas no primeiro ano, de acordo com o modelo quadrático. Estimou-se valor mínimo de $73,1 \%$ para a dose de $153,9 \mathrm{~kg} / \mathrm{ha}$ de $\mathrm{N}$. Não se vislumbrou explicação para os menores teores de DIVMS estimados em dose intermediária. Diferentemente, no segundo ano, não houve efeito $(\mathrm{P}>0,05)$ da adubação nitrogenada no coeficiente de DIVMS, com valor médio igual a $70,8 \%$. Estes resultados são bastante satisfatórios para uma forrageira tropical que, em geral, apresenta baixos coeficientes de DIVMS. É provável que o adequado manejo do pastejo adotado neste experimento tenha contribuído para a melhoria dos coeficientes de DIVMS da forragem potencialmente consumida.

A adubação nitrogenada elevou linearmente $(\mathrm{P}<0,05)$ a TL da pastagem (Tab. 5). A elevação da dose de $\mathrm{N}$ de 75 para $300 \mathrm{~kg} / \mathrm{ha}$ resultou em incremento de 3,6 para 5,3UA/ha e de 3,7 para $5,2 \mathrm{UA} / \mathrm{ha}$ no primeiro e segundo anos, respectivamente. Estes resultados são bastante expressivos e refletem o efeito da adubação nitrogenada no aumento da produção de forragem na pastagem. Fica evidenciado, assim, que a $B$. decumbens cv. Basilisk apresenta bom potencial de resposta à adubação nitrogenada, podendo ser utilizada também em sistemas de produção de médio a alto nível tecnológico. Isso contraria os comuns e frequentes argumentos de que a $B$. decumbens não responde ou apresenta baixa resposta à adubação nitrogenada e, por isso, deve ser recomendada apenas para sistemas extensivos de produção animal. 
Tabela 5. Equações de regressão ajustadas para a taxa de lotação (TL), ganho de peso médio diário (GMD) e produção animal por área (PA) em pastagens Brachiaria decumbens em função das doses de N, no primeiro e segundo anos

\begin{tabular}{lcc}
\hline Característica & Equação de regressão & $\mathrm{R}^{2}$ \\
\hline TL (UA/ha) & Primeiro ano & 0,82 \\
GMD (kg/dia.novilho) & $\hat{Y}=3,06+0,00756 * \mathrm{~N}$ & - \\
PA (kg/ha) & $\bar{Y}=0,551$ & 0,97 \\
TL (UA/ha) & $\hat{Y}=293,04+1,48276 * \mathrm{~N}$ & 0,96 \\
GMD (kg/dia.novilho) & Segundo ano & - \\
PA (kg/ha) & $\hat{Y}=3,20+0,00652 * \mathrm{~N}$ & 0,91 \\
\hline Significativo pelo teste $(\mathrm{P}<0,05)$ & $\bar{Y}=0,679$ &
\end{tabular}

* Significativo pelo teste $\mathrm{t}(\mathrm{P}<0,05)$.

Não houve influência $(\mathrm{P}>0,05)$ da dose de $\mathrm{N}$ no ganho de peso médio diário individual dos novilhos (GMD) (Tab. 5), registrando-se médias de 0,551 e $0,679 \mathrm{~kg} /$ dia.novilho no primeiro e segundo anos, respectivamente. Euclides et al. (2007), ao avaliarem a eficiência biológica e a econômica de pasto de capim-tanzânia adubado com nitrogênio no final do verão, também verificaram pouca consistência da adubação nitrogenada sobre o desempenho dos bovinos. A ausência de efeito da adubação nitrogenada sobre o desempenho animal pode ser explicada pelo fato de o pasto de capim-braquiária ter sido cortado à mesma altura, caracterizando intensidade de pastejo similar em todos os tratamentos.

Cabe ressaltar, entretanto, que, apesar de não ser significativa $(\mathrm{P}>0,05)$, a diferença no GMD dos novilhos, nos valores médios de 0,485 e $0,623 \mathrm{~kg} /$ dia.novilho e 0,610 e $0,753 \mathrm{~kg} /$ dia.novilho, para as doses de $75 \mathrm{e}$ $300 \mathrm{~kg} / \mathrm{ha}$ de $\mathrm{N}$, no primeiro e segundo anos, respectivamente, representa lucro, ou prejuízo para o criador. $\mathrm{O}$ aumento de 0,138 e $0,143 \mathrm{~kg} /$ dia.novilho entre as doses extremas, no primeiro e segundo anos, respectivamente, pode ser atribuído ao maior percentual de PB (Tab. 4) na forragem potencialmente consumível existente no pasto sob maior dose de $\mathrm{N}$. Ademais, a maior MFV presente nos pastos adubados com doses mais altas de $\mathrm{N}$ (Tab. 3) pode ter otimizado o comportamento ingestivo dos novilhos devido à elevação da densidade da forragem verde, conforme já explicado anteriormente.

Para a PA constatou-se efeito linear e positivo da aplicação de $\mathrm{N}(\mathrm{P}<0,05)$, expressa em kg/ha, nos dois anos (Tab. 5). Os valores foram de 404,2 e $737,9 \mathrm{~kg} / \mathrm{ha}$ e de 619,7 e $1.008,4 \mathrm{~kg} / \mathrm{ha}$, para as doses de 75 e $300 \mathrm{~kg} / \mathrm{ha}$, no primeiro e segundo anos, respectivamente. Essa resposta é reflexo direto do aumento na TL da pastagem, o que também foi observado por Euclides et al. (2007).

As eficiências de uso do $\mathrm{N}$ fertilizante nas pastagens de $B$. decumbens foram de $1,5 \mathrm{e}$ $1,7 \mathrm{~kg}$.ha de peso corporal $/ \mathrm{kg}$.ha de $\mathrm{N}$ aplicado no primeiro e segundo anos, respectivamente. Estes resultados assemelham-se aos relatados por Martha Jr. et al. (2004), em revisão de literatura, cujo valor médio foi de $1,45 \mathrm{~kg}$.ha de peso corporal $/ \mathrm{kg}$.ha de $\mathrm{N}$ aplicado, para um potencial estimado em 3,5 a 4,0kg.ha de peso corporal/kg.ha de $\mathrm{N}$ aplicado.

\section{CONCLUSÕES}

A adubação nitrogenada aumenta a massa de forragem, a taxa de lotação e a produção animal por área em pastagem de Brachiaria decumbens cv. Basilisk manejada sob lotação contínua com taxa de lotação variável. 


\section{REFERÊNCIAS BIBLIOGRÁFICAS}

ALVIN, M.J.; BOTREL, M.A. Efeitos de doses de nitrogênio na produção de leite de vacas em pastagem de coast-cross. Pesq. Agropec. Bras., v.36, p.577-583, 2001.

BARTHRAM, E.; DUFF, G.T.I.; ELSTON, D.A. et al. Frequency distributions of sward height under sheep grazing. Grass Forrage Sci., v.60, p.4-16, 2005.

CAVALCANTE, M.A.B. Características morfogênicas, estruturais e acúmulo de forragem em relvado de Brachiaria decumbens cv. Basilisk sob pastejo, em diferentes alturas. 2001. 64f. Dissertação (Mestrado) - Universidade Federal de Viçosa,Viçosa, MG.

CORREA, L.A.; CANTARELLA, H.; PRIMAVESI, A.C. et al. Efeito de fontes e doses de nitrogênio na produção e qualidade da forragem de capim-coastcross. Rev. Bras. Zootec., v.36, p.763-772, 2007.

EUCLIDES, V.P.B.; COSTA, F.P.; MACEDO, M.C.M. et al. Eficiência biológica e econômica de pasto de capim-tanzânia adubado com nitrogênio no final do verão. Pesq. Agropec. Bras., v.42, p.1345-1355, 2007.

FAGUNDES, J.L.; FONSECA, D.M.; GOMIDE, J.A. et al. Acúmulo de forragem em pastos de Brachiaria decumbens adubados com nitrogênio. Pesq. Agropec. Bras., v.40, p.397-403, 2005.

FAGUNDES, J.L.; FONSECA, D.M.; MORAES, R.V. et al. Avaliação das características estruturais do capim-braquiária em pastagens adubadas com nitrogênio nas quatro estações do ano. Rev. Bras. Zootec., v.35, p.1-5, 2006.

KÖPEN, W. Climatologia. Buenos Aires: Gráfica Panamericana, 1948. 478p.

LUGÃO, S.M.B.; RODRIGUES, L.R.A.; ABRAHÃO, J.J.S. et al. Acúmulo de forragem e eficiência de utilização do nitrogênio em pastagens de Panicum maximum Jacq. (Acesso BRA-006998) adubadas com nitrogênio. Acta. Sci. Anim. Sci., v.52, p.371-379, 2003.

MACEDO, M.C.M. Análise comparativa de recomendações de adubação em pastagens. In: SIMPÓSIO SOBRE MANEJO DA PASTAGEM, 21., 2004, Piracicaba, SP. Anais... Piracicaba, SP: FEALQ, 2004. p.317-356.
MARTHA Jr., G.B.; VILELA, L.; BARIONI, L.G. et al. Manejo da adubação nitrogenada em pastagens. In: SIMPÓSIO SOBRE MANEJO DA PASTAGEM, 21., 2004, Piracicaba, SP. Anais... Piracicaba, SP: FEALQ, 2004. p.155216.

MISTURA, C.; FONSECA, D.M.; MOREIRA, L.M. et al. Efeito da adubação nitrogenada e irrigação sobre a composição químicobromatológica das lâminas foliares e da planta inteira de capim-elefante sob pastejo. Rev. Bras. Zootec., v.36, p.1707-1714, 2007.

MORAES, R.V.; FONSECA, D.M.; NASCIMENTO JÚNIOR, D. et al. Demografia de perfilhos basilares em pastagem de Brachiaria decumbens adubada com nitrogênio. Rev. Bras. Zootec., v.35, p.380-388, 2006.

SANTOS, M.E.R.; FONSECA, D.M.; BALBINO, E.M. et al. Capim-braquiária diferido e adubado com nitrogênio: produção e características da forragem. Rev. Bras. Zootec., v.38, p.650-656, 2009.

SILVA, D.J.; QUEIROZ, A.C. Análise de alimentos: métodos químicos e biológicos. 3.ed. Viçosa: UFV, 2002. 235p.

VAN SOEST, P.J. Voluntary intake relation to chemical composition and digestibility. J. Anim. Sci., v.24, p.834-844, 1965.

SISTEMA de análises estatísticas e genéticas. Versão 8.1. Viçosa, MG, 2003.

STOBBS, T.H. The effect of plant structure on the intake of tropical pastures.III. Influence of fertilizer nitrogen on the variation in the bite size of bite harvested by jersey cows grazing Setaria anceps cv. Kazungula swards. Aust. J. Agric. Res., v.26, p.997- 1007, 1975.

VITOR, C.M.T.; FONSECA, D.M.; CÓSER, A.C. et al. Produção de matéria seca e valor nutritivo de pastagem de capim-elefante sob irrigação e adubação nitrogenada. Rev. Bras. Zootec., v.38, p.435-442, 2009. 